\title{
Frequency and characteristics of Internet use by Spanish teenagers. A cross-sectional study
}

\author{
Ricardo E. Reolid-Martínez, M.D., ${ }^{a}$ María Flores-Copete, M.D., ${ }^{a}$ \\ Mónica López-García, M.D., ${ }^{a}$ Pilar Alcantud-Lozano, M.D., ${ }^{a}$ \\ M. Candelaria Ayuso-Raya, M.D., ${ }^{a}$ and Francisco Escobar-Rabadán, M.D. ${ }^{a}$
}

\begin{abstract}
Introduction. Internet has completely changed communication among people in today's world, especially among young users. The objective of this study is to establish the frequency of Internet use by teenagers, and most used apps.

Population and methods. This was a crosssectional study. In November 2013, students attending two mandatory secondary schools in Albacete were invited to complete a selfadministered questionnaire with close-ended and open questions. Questionnaires were completed in the classroom, either "online" or "with pen and paper". Answers were entered in a computer database using theSPSS17.0 software. Statistical analysis included a comparison of proportions ( 2 test) and mean/median values (Student's t test/non-parametric tests).

Results. Nine hundred and sixty-seven students participated; their mean age was 13.8 years old (range: 11-20); $53.5 \%$ were girls. Most students $(70.9 \%)$ lived in the city. Most belonged to a middle (51.3\%) and high (34.8\%) socioeconomic status. Also most students went online on a daily basis $(73.4 \%)$; only $0.9 \%$ indicated that they never did. The most frequently used apps included WhatsApp $(77.1 \%)$, social networks $(70.1 \%)$ and musicapps $(66.6 \%)$. Among girls, themostcommon Internet use was social networks $(p=0.004)$, WhatsApp $(p<0.0001)$, Instagram $(p<0.0001)$ and listening to music $(p=0.004)$. Boys most commonly used the Internet to browse the web $(p<0.0001)$, Skype $(p=0.001)$, play $(p<0.0001)$ and watch movies or TV shows $(p=0.035)$.

Conclusions. Internet takes up a large part of the time in adolescents' lives, especially as a means of communications, being WhatsApp and social networks the most commonly used apps.

Key words: adolescent, Internet, means of social communication, computers, mobile phone.
\end{abstract}

a. University Health of Albacete. Albacete, Spain.

E-mail Address:

Francisco Escobar-

Rabadán, M.D.: jescobarr@

sescam.jccm.es

Funding:

None.

Conflict of interest:

None.

Received: 6-18-2015

Accepted: 8-10-2015 http://dx.doi.org/10.5546/aap.2016.eng.6

\section{INTRODUCTION}

The widespread use of new information and communication technologies (ICT) has transformed relationships among people in today's world, especially among youth. For most of them, web browsing, using virtual social networks, video games and mobile phones resulted in a radical change in how they communicate. ${ }^{1}$ Internet apps offer youth new opportunities to be creative and to learn, together with the possibility of making exchanges and horizontal communication. ${ }^{2}$ The advantages offered by Internet are undeniable, but it may bring a degree of dependence that could have an effect on daily life. ${ }^{3}$

During adolescence, a search for instant gratification and curiosity for new experiences converge with a feeling of invulnerability, making adolescents to be more exposed to risky behaviors. "Internet addiction" has been described and consequently developed in the scientific literature in relation to its impact on mental health, ${ }^{5,6}$ beyond its potential commercial uses to disseminate and sell different products (alcohol, tobacco, music, violent games, etc.). ${ }^{7}$ The DSM-V has now included the so-called Internet gaming disorder. Together with this welldefined clinical condition, excessive Internet use has also been described, and although it is not considered a psychopathological disorder, it has negative consequences on the educational or family setting. ${ }^{8}$

An association has been identified between Internet addiction and different psychopathological disorders, 9,10 which may cause psychiatric comorbidity on $13 \%$ $26 \%$ of patients with this condition, ${ }^{11}$ as well as with certain personality traits (introversion, depression, aggressiveness, substance abuse) that may predispose patients to social isolation, thus making them more susceptible to excessive Internet use. ${ }^{12}$

The main objective of this study is to establish the frequency of Internet use by teenagers, and most used apps. 
In addition, the following secondary objectives have been proposed:

- To know the frequency of social network use by teenagers and the most commonly used social networks.

- To establish Internet use strategies by teenagers that may imply a risk for them, their families or computer equipment.

- To know the opinion of teenagers on parental control regarding Internet use and establish possible avoidance strategies used by them.

\section{POPULATION AND METHODS}

This was a cross-sectional study. The sample size was estimated to be 865 , for an expected proportion of Internet use of $90 \%$, with a $+2 \%$ accuracy level and a 95\% confidence level.We opted to use a convenience sample: students from two schools that were easily accessible to investigators and whose number of students would fulfill the required size more than enough. The project was approved by the authorities of both schools where it was conducted.

In November 2013, students attending two mandatory secondary schools in Albacete were invited to complete a self-administered questionnaire (Annex) with close-ended and open questions. The questionnaire was specifically designed based on the information found in a literature review and in accordance with the study objectives. It also recorded data on age, sex, place of residence and parents' employment, which were used to estimate participants' socioeconomic status. $^{13}$

- Class I: executive, professional.

- Class II: manager, business owner, lessqualified professional.

- Class III: mid-level professional, office clerk, government employee.

- Class IVa: qualified manual worker.

- Class IVb: semi-qualified manual worker.

- Class V: unqualified worker.

- Class VI: other (unemployed, retired, housewife). Each student was assigned the code corresponding to the highest qualification of his/ her father and/or mother (for example, if his/her father was a qualified manual worker and his / her mother was an office clerk, the corresponding code was 3). In order to facilitate the use of this outcome measure with a lower number of categories, codes were grouped as follows: 1 and 2: high and middle-high class. 3: middle class. 4-7: middle-low and low class.
A pilot test was conducted with 11 voluntary students from other schools. This allowed to correct hardly comprehensible or confusing terms.

The students who participated in the study completed the questionnaire in their classrooms, either "online" or "with pen and paper", once their parents and teachers had provided their informed consent and students had given their assent. At least one of the investigators was present during the administration of the questionnaire in order to facilitate completion and clear any doubts.

Answers were coded and entered in a computer database using the SPSS 17.0 software. Statistical analysis included a comparison of proportions ( $\chi^{2}$ test) and median values (Student's $t$ test) for continuous outcome measures with normal distribution, and non-parametric tests for those with an abnormal distribution. A logistic regression analysis was used to study the relationship between the frequency of connection to Internet and social network use and the different recorded sociodemographic outcome measures.

\section{RESULTS}

Nine hundred and sixty-seven students completed the questionnaire; no one refused to participate. Table 1 describes their sociodemographic characteristics. Their age ranged from 11 to 20 years old, and there was a slight predominance of girls, with no significant differences between both schools for these outcome measures. There were no significant differences in terms of age between boys and girls.

Most students went online on a daily basis (Table 2). The two extreme options (connect occasionally/several hours a day) were the most common among girls $(p=0.0002)$. Students from a least-favored socioeconomic status tended to connect either never or less than weekly $(20.8 \%)$ compared to middle- and high-class students $(14.6 \%$ and $14.1 \%$, respectively; $p=0.03)$. Frequency of connection increased directly with age, with a median of 12 years old (interquartile range [IQR]: 12-14) for those who never connected to the Internet and 15 years old (IQR: 14-15) for those who stated that they were almost always connected $(p<0.0001)$. No significant differences were observed between both schools or by place of residence in terms of frequency of connection to the Internet. 
The most widely used apps were WhatsApp (77.1\%; 95\% confidence interval [CI]: 74.4\%$79.8 \%)$, social networks $(70.1 \% ; 95 \%$ CI: $67.2 \%-73.1 \%)$ and music apps $(66.6 \% ; 95 \%$ CI:63.6\%-69.6\%). Figure 1 shows the frequency of use of the different apps in each school, while Figure 2 shows it by place of residence. Table 2 details differences in app use by gender. There was a greater likelihood ( $p<0.0001)$ of using certain apps at an older age: movies, music, Instagram, WhatsApp and social networks, as well as browsing the web $(p=0.014)$. In terms of socioeconomic status, significant differences $(p=0.007)$ were observed only in relation to social network use: $75.5 \%$ among middle-class participants versus $68.9 \%$ among high-class students and $62.0 \%$ among low-class kids.

Among social networks, 579 users who

TABLE 1.Sociodemographic characteristics of students participating in the study. Age is described as mean years old (standard deviation), the remaining outcome measures are expressed as relativef requency (\%)

\begin{tabular}{|c|c|c|c|}
\hline & $\begin{array}{c}\text { Universidad } \\
\text { Laboral }(n=559)\end{array}$ & $\begin{array}{c}\text { School } \\
\text { No. } 7(n=408) \\
\end{array}$ & Total $(n=967)$ \\
\hline Age & 13.8 (1.4) [NR: 52] & 13.7 (1.4) [NR: 12] & 13.8 (1.4) [NR: 64] \\
\hline \multicolumn{4}{|l|}{ Sex } \\
\hline Girls & $279(54.5)$ & $210(52.2)$ & $489(53.5)$ \\
\hline Boys & $233(45.5)$ & $192(47.8)$ & $425(46.5)$ \\
\hline NR & 47 & 6 & 53 \\
\hline \multicolumn{4}{|l|}{ Socioeconomic status } \\
\hline High and middle-high & $144(29.4)$ & $158(41.7)^{*}$ & $302(34.8)$ \\
\hline Middle & $72(14.7)$ & $80(21.1)$ & $152(17.5)$ \\
\hline Middle-low and low & $273(55.8)$ & $141(37.2)^{*}$ & $414(47.7)$ \\
\hline NR & 70 & 29 & 99 \\
\hline \multicolumn{4}{|l|}{ Place of residence } \\
\hline Urban & $290(57.8)$ & $396(99.0)^{*}$ & $686(76.1)$ \\
\hline Rural & $212(52.2)$ & $4(1.0)^{*}$ & $216(23.9)$ \\
\hline NR & 57 & 8 & 65 \\
\hline
\end{tabular}

n: number of subjects.

NR: not reported.

* $\mathrm{p}<0.0001$.

TABLE 2.Frequency of connection to the Internet and most commonly used apps by sex (\% for each sex)

\begin{tabular}{lccc}
\hline & Girls & Boys & Total \\
\hline Frequency of connection & $5(1.0)$ & $4(1.0)$ & $9(1.0)$ \\
Never & $56(11.5)^{*}$ & $25(6.0)$ & $9(1.0)$ \\
Occasionally & $19(3.9)$ & $31(7.5)$ & $50(5.5)$ \\
Weekly & $64(13.2)$ & $65(15.6)$ & $129(14.4)$ \\
Several days a weeks & $82(42.8)$ & $106(25.5)$ & $188(20.8)$ \\
Daily, $<$ 1 hour & $208(42.8)$ & $155(37.3)$ & $363(40.3)$ \\
Several hours a day & $50(10.7)$ & $30(7.1)$ & $82(9.1)$ \\
Continuously & & & $239(26.2)$ \\
Apps & $115(23.6)$ & $124(29.2)$ & $419(46.0)$ \\
E-mail & $181(37.2)$ & $238(56.1)^{* *}$ & $272(29.9)$ \\
Web & $141(29.0)$ & $131(30.9)$ & $106(11.6)$ \\
Chat & $50(10.3)$ & $56(13.2)$ & $211(23.2)$ \\
Contacts & $92(18.9)$ & $119(28.1)^{* * *}$ & $649(71.0)$ \\
Skype & $367(75.1)^{* * *}$ & $282(66.4)$ & $718(78.8)$ \\
Social networks & $409(84.0)^{* *}$ & $309(72.9)$ & $196(21.5)$ \\
WhatsApp & $150(30.7)^{* *}$ & $46(10.8)$ & $313(34.3)$ \\
Instagram & $84(17.2)$ & $229(54.0)^{* *}$ & $626(68.7)$ \\
Video games & $355(72.9)^{* * *}$ & $144(34.0)^{* * * *}$ & $278(30.5)$ \\
Music & $134(27.5)$ & & \\
Movies/TV shows & & & \\
\hline
\end{tabular}

${ }^{*} \mathrm{p}=0.0002 ;{ }^{* *} \mathrm{p}<0.0001 ;{ }^{* * *} \mathrm{p}<0.01 ;{ }^{* * * *} \mathrm{p}<0.05$ 
indicated their favorite ones chose Twitter $(71.2 \%$; 95\% CI: 67.4-74.9), followed by Tuenti (58:7\%; 95\% CI: 54.6-62.8) and Facebook (20.9\%; 95\% CI: 17.5-24.3).

Some participants used other social networks, either through Google (Hangouts) or Yahoo (Messenger), or Ask, Chatroulette, Heello, Tumblr, Habbo, Wattpad, Metroflog, although at a smaller level. Combined use of more than one social network was common, with a predominance of Twitter and Tuenti in 34.3\%.
Twitter was most commonly used by girls $(p=0.007)$, and Facebook, by boys $(p=0.024)$, but there was no difference by sex in relation to Tuenti. In terms of age, it was significantly more likely $(p<0.0001)$ that Tuenti users were younger (median and IQR: 14 and13-15 vs. 15 and 14-15) and that Twitter users were older than those who did not use these apps (median and IQR: 14 and $13-15$ vs. 13 and 1215). There were no differences in social network use by place of residence or socioeconomic

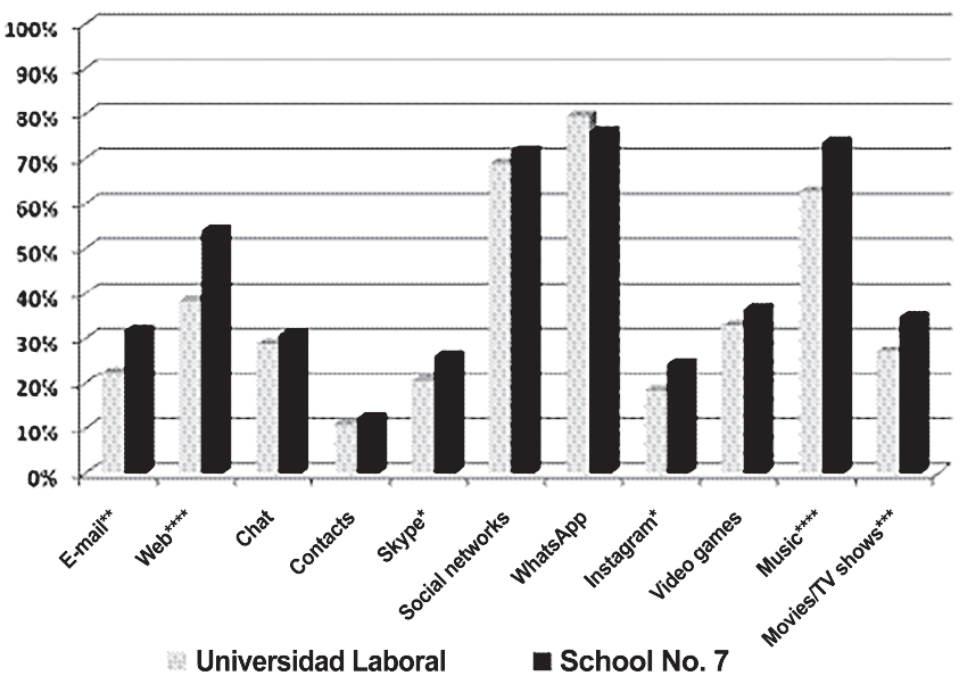

${ }^{*} \mathrm{p}<0.05 ;{ }^{* *} \mathrm{p}<0.01 ;{ }^{* * *} \mathrm{p}<0.001 ;{ }^{* * *} \mathrm{p}<0.0001$

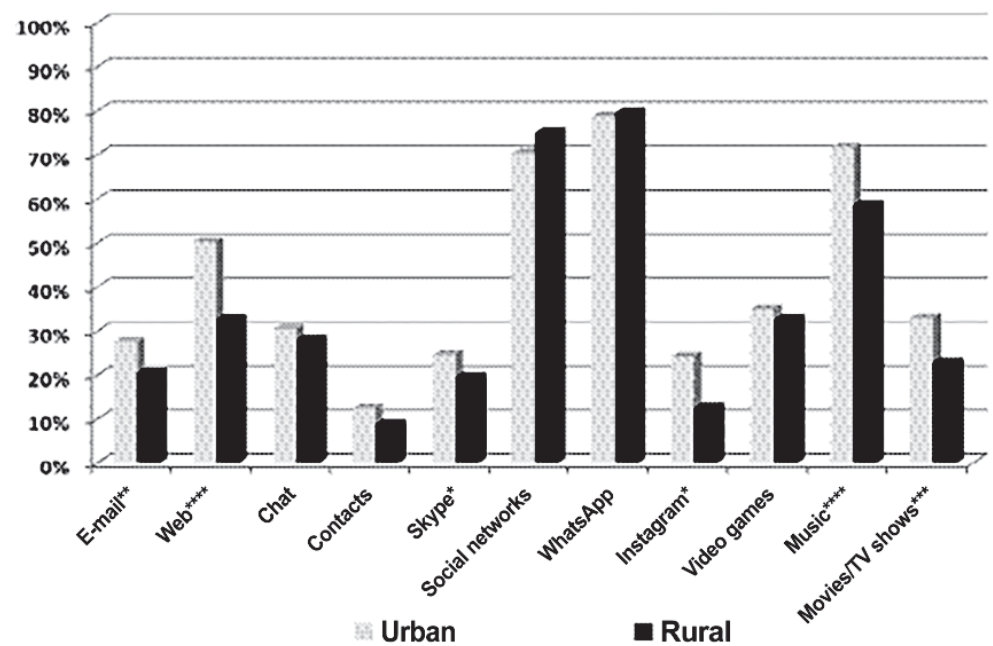

${ }^{*} \mathrm{p}<0.05 ;{ }^{* *} \mathrm{p}<0.01 ;{ }^{* * *} \mathrm{p}<0.0001$. 
status. Also, there were no significant differences between both schools in terms of Twitter and Tuenti use, and only Facebook use was observed to be more common at Universidad Laboral: $24.0 \%$ vs. $16.5 \%$ ( $p=0.028$ ).

Table 3 describes the results of the logistic regression analysis, which show that daily connection to Internet is independently associated with age and socioeconomic status, and that social network use is also associated with sex, since girls tend to make a greater use of them.

Figure 3 shows the percentage of risky behaviors and differences by gender. Only $5.9 \%$ denied the existence of risks posed by the Internet. As well, $67.3 \%$ of students considered that chatting implied a risk, and it is worth noting that $95.7 \%$ of participants were worried about being contacted by strangers, invasion of their privacy, and bullying. Sharing passwords was considered unsafe by $84.5 \%$. Although $46.6 \%$ of students said they had found photos of them in social networks that they did not want there, $44.9 \%$ admitted that they posted photos of other people. "Friendship requests" were accepted by $58.8 \%$ only if they were from people they knew personally. About $12.2 \%$ indicated that they had ever felt insulted in social networks, while $8.3 \%$ admitted that they had been involved in cyberbullying, either as a victim, a bully or both.

Around 75.6\% (95\% CI: 72.8-78.4) believed that their parents trusted how they used the Internet, and $11.8 \%$ (95\% CI: 9.7-13.9) thought that their parents only knew part of what they did online. Concern about having their parents see what they did online was expressed by $65.5 \%$, while $36.3 \%$ did not agree with parental control (their "privacy" was commonly referred to in open questions). However, 59.7\% agreed with parental control, shared their passwords or had their parents as members of their social networks.

Only 30.5\% (95\% CI: 27.5-33.5) did not use any strategy to conceal their online activities. The most common strategy was deleting their browsing history $(36.3 \%)$, followed by accessing the Internet only from a mobile phone or tablet $(28.3 \%)$, minimizing browsers and windows when an adult approached (27.8\%), and hiding or deleting chats $(25.6 \%)$.

Only $6.9 \%$ (95\% CI: 5.3-8.6) said that they did not have a mobile phone (some even stated that they were not interested). Nevertheless, $81.5 \%$ of respondents (95\% CI: 78.9-84.0) frequently used this device to access the Internet. However, mobile phone users attributed many more uses to this device (in some open questions, they answered that mobile phones were used "for everything"). In relation to communicating, the following uses were described, by order of frequency: WhatsApp (88.4\%), calls $(81.8 \%)$, SMS (45.3\%) and e-mail (27.8\%). Mobile phones were also significantly used in relation to music $(83.4 \%)$, games $(52.2 \%)$ or as a calendar $(32.7 \%)$, followed by a long list of other uses, including camera, alarm clock or flashlight.

TABLE 3. Binary logistic regression analysis for dependent outcome measures: frequency of connection (daily vs. less frequently), use of social networks (yes vs. no), for overall use and specific Twitter, Tuenti and Facebook use

\begin{tabular}{|c|c|c|c|}
\hline Dependent outcome measure & Independent outcome measures & OR & $95 \% \mathrm{CI}$ \\
\hline \multirow{4}{*}{$\begin{array}{l}\text { Frequency of connection } \\
\text { (daily vs. less frequently) }\end{array}$} & Age & 1.8 & $1.6-2.2$ \\
\hline & Socioeconomic status (vs. low status) & & \\
\hline & High & 2.1 & $1.2-3.8$ \\
\hline & Middle & 1.9 & $1.1-3.3$ \\
\hline \multirow{5}{*}{$\begin{array}{l}\text { Use of social networks } \\
\text { (yes vs. no) }\end{array}$} & Age & 1.6 & $1.4-1.8$ \\
\hline & Socioeconomic status (vs. low status) & & \\
\hline & High & 1.9 & $1.1-3.0$ \\
\hline & Middle & 2.4 & $1.5-3.8$ \\
\hline & Sex (girls vs. boys) & 1.8 & $1.3-2.5$ \\
\hline Twitter use & Age & 1.6 & $1.4-1.9$ \\
\hline (yes vs. no) & Sex (girls vs. boys) & 2.0 & $1.3-2.9$ \\
\hline $\begin{array}{l}\text { Tuenti use } \\
\text { (yes vs. no) }\end{array}$ & Age & 0.6 & $0.6-0.7$ \\
\hline \multirow{2}{*}{$\begin{array}{l}\text { Facebook use } \\
\text { (yes vs. no) }\end{array}$} & Sex (girls vs. boys) & 0.6 & $0.4-0.9$ \\
\hline & School (Laboral vs. No. 7) & 1.7 & $1.1-2.6$ \\
\hline
\end{tabular}




\section{DISCUSSION}

The results of this study evidence that the Internet takes up a large part of the time in adolescents' lives, especially as a means of communications, being WhatsApp and social networks, in particular Twitter, the most commonly used apps. Mobile phones are used by the overwhelming majority of teenagers and have become an essential tool in their daily life activities. Teenagers express themselves with and through their mobile phones; it is a sign of their identity that has allowed them to reach their communication independence. ${ }^{1}$

This study provides an update on usage trends in the constantly changing setting of new technologies. However, potential geographic or cultural differences should be regarded as possible limitations because they may define patterns of use, even in spite of the globalization that prevails in today's world.

In Spain, the 2014 National Health Survey, ${ }^{14}$ indicated that Internet use, especially computer use, is a widespread habit even earlier than at 10 years old. In $74.4 \%$ of homes there is access to Internet, computer use by children reaches $93.8 \%$, while $92.0 \%$ use the Internet. The availability of a mobile phone increases as of 10 years old, until reaching $90.3 \%$ at 15 years old.

Data from a study conducted in Madrid confirm the association between a high Internet use and mobile phone use, therefore reinforcing the idea of an overall alteration in behavior brought about by these new ICT. In addition, an increased Internet use has been related to substance use, especially alcohol or cannabis. ${ }^{7}$

Another study conducted in different schools from Burgos that included 2063 interviews with adolescents aged between 10 and 18 years old showed that ICT use was widespread, and could even be considered mass use: $10 \%$ of teenagers admitted that they abused ICT. ${ }^{15}$

In Europe, Durkee, et al. ${ }^{16}$ have described Internet addiction prevalences ranging from $2 \%$ in Norway to $18.3 \%$ in England. They also found a greater risk among people from disadvantaged areas and cultural minorities, while religion may have acted as a protective factor. In terms of sex, male teenagers may show more pathological behaviors in relation to Internet use. Anyhow, youth at a higher risk of Internet abuse who may develop addictive behaviors are those with lack of psychological and emotional support, as well as those with low self-esteem or problems adapting to their environment. ${ }^{7}$ In addition, Tsitsika, et al. ${ }^{17}$ have demonstrated that teenagers whose parents have a high cultural level had a lower possibility of making an inadequate use of Internet.

Our results underscore different preferences in terms of social networks associated with age, sex and socioeconomic status. According to Pujazon-Zazik and Park, ${ }^{18}$ we may distinguish three stages during adolescence, each associated

FIGURE 3. Percentage of "risky activities" done online (in order to counteract the negative impact of certain answers, neutral answers like "looking for information on a subject" were used for masking) among girls and boys

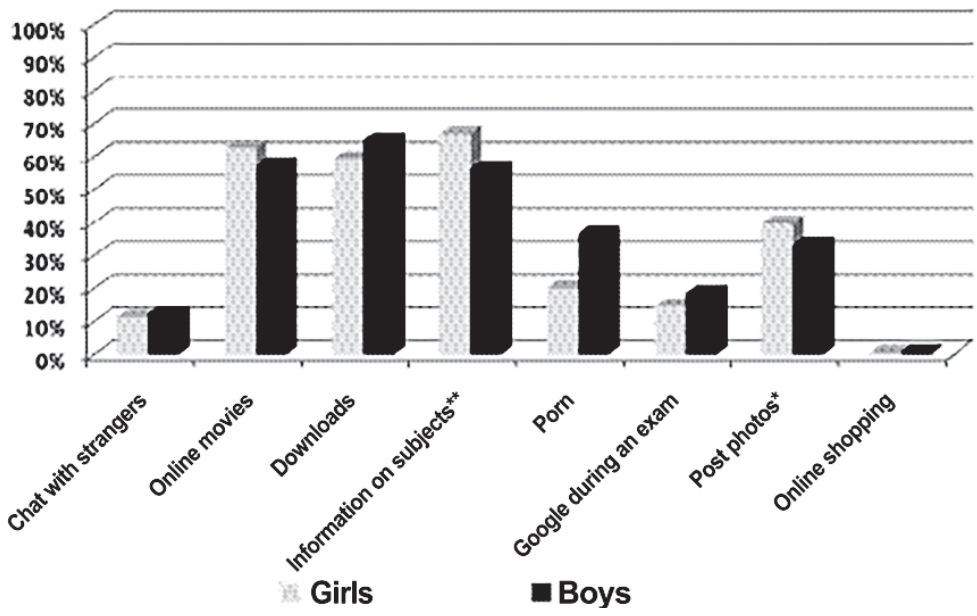

${ }^{*} \mathrm{p}<0,05 ;{ }^{* *} \mathrm{p}<0,01 ;{ }^{* * *} \mathrm{p}<0,0001$. 
with different needs that may be extrapolated to Internet surfing. Early adolescence (10-13 years old) is characterized by the acquisition of an independent behavior. Middle adolescence (14-17 years old) includes an early desire to attract the opposite sex and interest in it (this stage implies a higher possibility of chatting with strangers and a risk of sexual harassment). Late adolescence (17-21 years old) involves a greater personal identity and independence from other people's views, as well as more interest in interpersonal relationships, notwithstanding group opinions, and a more responsible use.

A concern that has arisen in relation to social network use by teenagers is how it might affect body image. Adolescents with body image dissatisfaction and internalization of a thin body ideal may make a greater use of photo apps, which would in turn exacerbate pre-existing body image disorders. ${ }^{19}$ Another risk attributed to social network use is a greater sexual promiscuity. In this regard, having a Facebook account has been associated to having multiple partners in the previous year, as well as having partners of various ages. ${ }^{20}$

An overwhelming majority of teenagers included in our study admitted that Internet use poses certain risks, especially in relation to potential bullying. However, this does not prevent them from following risky patterns. Most teenagers believe that their parents trust them in relation to what they do online. However, they frequently use concealment strategies.

The term "cyberbullying" is still under review. For this type of harassment to be considered, several criteria should be met, for example, purpose of hurting someone, a repetitive behavioral pattern, occurring in the context of technology use, anonymity and/or social life. This distinguishes "cyberbullying" from other forms of harassment that aim at a specific group of individuals (e.g., pedophilia) or at a random group (such us mass virus mailing). This has lead to the emergence of new terms, such as "cyberteasing" and "cyber-arguing". ${ }^{21}$

Parental supervision is considered a key protective factor. ${ }^{22}$ However, as demonstrated in the Youth and Information Technology and Communication study (Joves i Tecnologies de la Informació i la Comunicació, JOITIC), ${ }^{5}$ parental control is low and decreases with age. Such lack of parental supervision and scarce discipline, together with poor intra-familial relationships, have been described as some of the causes of Internet addiction. ${ }^{7}$ As pointed out by Şenormanc1, et al., ${ }^{8}$ families that solve their problems together, have emotional bonds, share roles, look after one another without limiting their freedom, have moderate control on their behaviors and communicate openly, easily and directly will be able to better face new challenges.

In short, we would like to highlight that the Internet takes up a large part of the time in adolescents' lives, especially as a means of communication, being WhatsApp and social networks the most commonly used apps; additionally, it is worth noting that in spite of knowing potential dangers, teenagers follow risky patterns anyway.

\section{REFERENCES}

1. Bercedo Sanz A, Redondo Figuero C, Pelayo Alonso R, Gómez Del Río Z, et al. Consumo de los medios de comunicación en la adolescencia. AnPediatr (Barc) 2005;63(6):516-25.

2. MiguelGonzález I, Echevarría BrozC, Ferrero FernándezE, Suárez Gil P. Uso de Internet por parte de los adolescentes de Gijón (Asturias) como fuente de información sobre salud. Aten Primaria 2011;43(6):281-6.

3. Cho H, Kwon M, Choi JH, Lee SK, et al. Development of the Internet addiction scale based on the Internet Gaming Disorder criteria suggested in DSM-5. Addict Behav 2014;39(9):1361-6.

4. Weinstein $\mathrm{A}$, Lejoyeux M. Internet addiction or excessive Internet use. Am J Drug Alcohol Abuse 2010;36(5):277-83.

5. Muñoz-Miralles R, Ortega-González R, Batalla-MartínezC, López-Morón MR, et al. Acceso y uso denuevas tecnologías entre los jóvenes de educación secundaria, implicaciones en salud. Estudio JOITIC. Aten Primaria 2014;46(2):77-88.

6. Lam-Figueroa N, Contreras-Pulache H, Mori-Quispe E, Nizama-Valladolid M, et al. Adicción a internet: desarrollo y validación de un instrumento en escolares adolescentes de Lima, Perú. Rev Peru Med Exp Salud Publica 2011;28(3):462-9.

7. Sánchez-Martínez M, Otero Puime A. Usos de internet y factores asociados en adolescentes de la Comunidad de Madrid. Aten Primaria 2010;42(2):79-85.

8. Şenormanc1 Ö, Şenormanc1 G, Güçlü O, Konkan R. Attachment and family functioning in patients with Internet addiction. Gen Hosp Psychiatry 2014;36(2):203-7.

9. Ko CH, Yen JY, Yen CF, Chen CS, et al. The association between Internet addiction and psychiatric disorder: a review of the literature. Eur Psychiatry 2012;27(1):1-8.

10. Carli V, Durkee T, Wasserman D, Hadlaczky G, et al. The association between pathological internet use and comorbid psychopathology: a systematic review. Psychopathology 2013;46(1):1-13.

11. Ho RC, Zhang MW, Tsang TY, Toh AH, et al. The association between internet addiction and psychiatric co-morbidity: a meta-analysis. BMC Psychiatry 2014;14:183.

12. Evren C, Dalbudak E, Evren B, Demirci AC. High risk of Internet addiction and its relationship with lifetime substance use, psychological and behavioral problems among 10th grade adolescents. Psychiatr Danub 2014;26(4):330-9.

13. Domingo Salvany A, Marcos Alonso J. Propuesta de un indicador de la clase social basado en la ocupación. Gac Sanit 1989;3(10):320-6. 
14. España. Ministerio de Sanidad, Servicios Sociales e Igualdad. Encuesta Nacional de Salud de España 2011/12. [Accessedon: January 27, 2015]. Available at: http:/ / www.msssi.gob.es/estadEstudios/estadisticas / encuestaNacional/.

15. Lara Ortega F, Fuentes Gómez M, de la Fuente Anuncibay R, Pérez del Río F, et al. Uso y abuso de las nuevas tecnologías. TrastorAdict 2010;12(1):2-4.

16. Durkee T, Kaess M, Carli V, Parzer P, et al. Prevalence of pathological internet use among adolescents in Europe: demographic and social factors. Addiction 2012;107(12):2210-22.

17. Tsitsika A, Janikian M, Schoenmakers TM, Tzavela EC, et al. Internet addictive behaviour in adolescence: a crosssectional study in seven European countries. Cyberpsychol Behav Soc Netw 2014;17(8):528-35.

18. Pujazon-Zazik M, Park MJ. To tweet, or not to tweet: gender differences and potential positive and negative health outcomes of adolescents' social internet use. Am J Mens Health 2010;4(1):77-85.

19. Meier EP, Gray J. Facebook photo activity associated with body image disturbance in adolescent girls. Cyberpsychol Behav Soc Netw 2014;17(4):199-206.

20. Kaufman ZA, Braunschweig EN, Feeney J, Dringus S, et al. Sexual risk behavior, alcohol use, and social media use among secondary school students in informal settlements in Cape Town and Port Elizabeth, South Africa. AIDS Behav 2014;18(9):1661-74.

21. Vandebosch H, Van Cleemput K. Defining cyberbullying: a qualitative research into the perceptions of youngsters. Cyberpsychol Behav 2008;11(4):499-503.

22. Strasburger VC, Jordan AB, Donnerstein E. Health effects of media on children and adolescents. Pediatrics 2010;125(4):756-67. 


\section{ANNEX}

This questionnaire is part of a study on information technology use by teenagers.

Participation is voluntary.

The questionnaire is absolutely anonymous; your answers will never be related to your identity.

It will only take you a few minutes to complete it.

Please check the answer that best correlates to you for each question.

1. How often do you go online?
a) Never.
b) Occasionally (once in a while, from time to time).
c) Less than once a week, but on a monthly basis.
d) At least once a week.
e) Several days a week.
f) On a daily basis, less than one hour.
g) Every day for several hours.
h) I do not spend more than one hour without going online.
i) Other (please specify):

2. If you have answered NEVER, what are the reasons? (If you have selected a different answer, continue to the next question).
a) I am not interested.
b) I do not need it.
c) I do not have a computer.
d) I have no Internet access.
e) It is too expensive.
f) Fear of viruses, hackers...
g) Fear of losing my privacy.
h) Other (please specify):

3. If you use the Internet, what kind of apps do you use? (You may select all the answers that apply).
a) E-mail.
b) Web browsing.
c) Chats.
d) Contacts.
e) Skype.
f) Social networks (please specify which):
g) WhatsApp.
h) Instagram.
i) Video games.
j) Music.
k) Movies.
1) Other: 
4. Have you ever connected to the Internet to do any of the following? (You may select severalanswers):
a) Talk with strangers (e.g., in a chat room).
b) Watch online movies.
c) Download anything.
d) Look for information in relation to my subjects.
e) Browse pornographic sites.
f) Google information during an exam.
g) Post photos.
h) Other (please specify):

5. What do you think your parents know about what you do online?
a) My parents trust me (on how I use the Internet).
b) My parents only know a part, not everything, of what I do online.
c) My parents have no time to supervise what I do online.
d) My parents do not care what I do online.
e) Other (please specify):

6. Are you worried that your parents might see what you do online?
a) No.
b) Yes.
c) I do not know.

7. How do you feel about parents potentially controlling Internet access?
a) I do not agree.
b) I share my passwords with my parents.
c) My parents (or one of them) are (is) part of my social network(s).
d) Other (please specify):

8. Do you think browsing the web poses any risk? (You may select all the answers that apply).
a) No.
b) Risks related to chatting with strangers.
c) Risks related to shopping online with credit cards.
d) Risks related to dissemination of personal information.
e) Risks related to virus infections.
f) Other (please specify):

9. Where do you access the Internet? (You may select all the answers that apply)
a) Wi-Fi areas.
b) Home.
c) Continuously on my mobile phone (or tablet).
d) Other (please specify):

10. What device do you usually use to go online? (You may select all the answers that apply).
a) Mobile phone.
b) Family PC.
c) Notebook/your own computer.
d) Other (please specify):

11. Do you have any of the following in your room? (You may select all the answers that apply).
a) TV.
b) Computer, with no access to Internet.
c) Computer (or smart phone or tablet) with no access to Internet.
d) Video game console.
e) None of these. 
12. Do you think watching online movies in sites like YouTube or Metacafe is safer than downloading movies (because they may contain a virus)?
a) Yes.
b) No.
c) I do not know.

13. Do you think bit streaming sites or file sharing software are legal?
a) Yes.
b) No.
c) I do not know.

14. Do you think bit streaming sites or file sharing software allow viruses to infect devices?
a) Yes.
b) No.
c) I do not know.

15. Do you think chatting online poses any risk?
a) Yes (please specify):
b) No.
c) I do not know.

16. Do you think it is safe to share your passwords (e.g., for online video games) with your friends?
a) Yes.
b) No.
c) I do not know.

17. What do you think about downloading articles from the web and submitting them in school as written by you? (You may select several answers).
a) It should not be considered stealing because the original author sold his/her work to the web site where it is published.
b) Teachers do not know how to use the Internet for this purpose, so they will never find out.
c) If I have no other choice (e.g., time constraints), it is worth taking the risk.
d) I do not agree with any of the above answers.

18. Do you usually post photos in social networks?
a) I post most of my photos.
b) I post only some photos, no matter who is in them.
c) I only post photos of me. If there are other people in them, I ask for their permission first.
d) I never post photos of me or my friends.

19. Have your friends posted photos of you in social networks?
a) Many times.
b) Sometimes.
c) Never.

20. When a friend of yours posts a photo of you in a social network, does he/she ask for your permission first?
a) Yes, always.
b) It depends on my friend.
c) No, they have never asked for my permission.
d) My friends do not post photos of me in the web. 
21. Have you ever seen a photo of you that you would have preferred had not been posted?
a) Many times.
b) Sometimes.
c) Never.

22. Do you accept all friendship requests you receive?
a) Yes, always, even if I do not know who they are.
b) I accept my friends and friends of my friends, even if I do not know them personally.
c) I only accept friends who I know personally.
d) I have sometimes accepted a request from a person I did not know.

23. Have you ever felt insulted or humiliated in any social network?
a) Yes, many times.
b) Yes, sometimes.
c) No, hardly ever.
d) No, never.

24. Have you ever been involved in a situation that may have been considered cyberbullying?
a) Yes, I have been a victim of cyberbullying.
b) Yes, I have bullied someone online.
c) Yes, I may have bullied someone online sometimes, and other times, I have been bulliedonline.
d) No.
e) I do not know.

25. What information do you provide in your social network profiles? (You may select several answers).
a) Sex.
b) Date of birth.
c) Place of origin.
d) City where you live at present.
e) Members of your family.
f) Love life.
g) Interests (boys/girls).
h) Looking for (friendship, meeting, relationship...).
i) Opinions (politics, religion...).
j) Activities that you are interested in (music, books, TV shows...).
k) Mobile phone number.
1) Address.
m) Other (please specify):

26. Has your computer ever gotten infected with a virus?
a) Never.
b) Yes (indicate the number of times that you remember):
c) I do not know. 
27. Do you use any of the following strategies? (You may select several answers):
a) Delete your Internet browsing history.
b) Minimize browsers and windows when an adult approaches.
c) Hide or delete chats.
d) Lie about what you do online.
e) Use a computer that your parents cannot access.
f) Connect to the Internet only using a mobile phone (or tablet).
g) Apply privacy settings so that your contents are visible only to who you want.
h) Use private browsing mode so as to leave no traces.
i) Have e-mail accounts that your parents are not aware of.
j) Have one or more fake social network profiles.
k) Other similar strategy (please specify):
l) I do not use any of these strategies.

28. How many hours a day do you spend doing the following from Monday through Friday?
a) Watching TV:
b) Using the Internet:
c) Using a mobile phone (including Internet):
d) Using a video game console:

29. How many hours a day do you spend doing the following on Saturdays, Sundays or holidays?
a) Watching TV:.
b) Using the Internet:
c) Using a mobile phone (including Internet):
d) Using a video game console:

30. What do you do with your mobile phone?
a) Calls.
b) WhatsApp.
c) Phone book.
d) Alarmclock.
e) Calendar.
f) Messages.
g) E-mail.
h) Games.
i) Music.
j) Calculator.
k) Other (please specify):
1) I do not have a mobile.

31. What type of video games do you play? (You may select several answers)
a) Shooting-fighting.
b) Sports.
c) Driving.
d) Adventures.
e) Other (please specify):
f) I do not play video games. 
32. Do you use the Internet in relation to medicine? (You may select several answers).
a) Look for information on diseases.
b) Look for information on symptoms you may have had.
c) Ask questions to other people (e.g., in a chat room).
d) Make appointments with your doctor.
e) Talk to your doctor.
f) Purchase medications.
g) Look for information to do homework for any of my subjects.
h) Other (please specify):

33. What do you think of the information about medicine that you may find online?
a) I think it is reliable.
b) If it is online, it is true.
c) Internet offers highly varying information, not everything is reliable.
d) I do not trust anything I read online.
e) Other (please specify):

34. If you have ever looked for information about medicine online, what topics do you remember searching for?

\section{Please provide the following information:}

- Age:

- Sex: female/male.

- Class:

- Father's employment:

- Mother's employment:

- Place of residence (town or city where you and your family live): 